\title{
Del enclave a la metrópolis: algunos problemas de la crítica poscolonial contemporánea ${ }^{1}$
}

\author{
Esteban Barboza Núñez ${ }^{2}$ \\ Universidad Nacional, Costa Rica
}

Resumen

Se analiza la crítica literaria denominada «poscolonialismo» o «estudios poscoloniales». Se traza la evolución de los estudios poscoloniales desde sus inicios hasta el presente, y las limitaciones que esta escuela presenta en cuanto a la formulación de sus enunciados y su aplicación en los contextos políticos, sociales y culturales de las literaturas que intenta abarcar. Asimismo, se of rece opciones para mejorar la práctica de los estudios poscoloniales, tanto en el campo de la crítica literaria como en el de la enseñanza de la literatura, especialmente en contextos más allá de la academia occidental.

\section{Abstract}

An analysis is carried out of the literary criticism labelled as postcolonialism or postcolonial studies. The evolution of postcolonialism is traced from its beginnings until today, including limitations in the formulation of theories and its application in the political, social and cultural contexts of the literatures covered. In addition, suggestions are made to enhance the practice of postcolonial studies, both from the field of literary criticism and the

Ponencia presentada en el I Congreso Internacional de Lingüística Aplicada, llevado a cabo en octubre de 2007, en el Campus Omar Dengo, de la Universidad Nacional de Costa Rica.

2 Correo electrónico: ezteban@hotmail.com 
teaching of literature, especially in contexts apart from the Western academic world.

Palabras clave: Estudios poscoloniales, análisis del discurso, crítica literaria, posmodernidad

Keywords: Postcolonial studies, discourse analysis, literary criticism, postmodernism

\section{Introducción}

La crítica y los estudios poscoloniales han pasado a ser términos de moda en círculos de crítica literaria contemporáneos, principalmente en Estados Unidos. Basta echar un vistazo a los departamentos de Literatura de algunas de prestigiosas universidades estadounidenses para encontrar docenas de cursos sobre teorías y literaturas poscoloniales. Según las descripciones de estos cursos, los estudios poscoloniales congregan los enfoques críticos y filosóficos más cuidadosamente elaborados y audaces para el estudio de la relación entre los pueblos poscoloniales y sus antiguos amos. Además, estos programas y cursos presentan a los estudios poscoloniales como constituyentes de un cuestionamiento articulado a la hegemonía Occidental.

Sin embargo, al pensar escépticamente en el ambiente de donde surge la mayoría de estas teorías — de la comodidad y la seguridad de la academia, especialmente la academia estadounidense-, es viable pensar en las congruencias (o incongruencias) entre estos enfoques y su práctica en lugares y situaciones ajenas a la vida académica Occidental. Esta ponencia se refiere a algunas limitaciones que presentan los estudios poscoloniales para el análisis literario en nuestro mundo contemporáneo, altamente conflictivo, globalizado y aparentemente poscolonial en el que las viejas formas de imperialismo parecen fusionarse con formas más nuevas, mortíferas y despiadadas, que combinan la violencia del pasado con las maquinaciones del 
capitalismo corporativo actual. La validez de algunos de los más importantes preceptos de las teorías poscoloniales se pone en entredicho aquí al contrastarse éstas con la realidad económica y social de los pueblos y contextos que supuestamente estudian a través del análisis textual.

\section{Definición de los estudios poscoloniales}

Tal y como lo indican muchos entendidos en el poscolonialismo, este término no es de fácil definición. Charles Bressler define al poscolonialismo como

un método para el análisis literario involucrado en el estudio de las literaturas escritas en inglés en países anteriomente colonizados... La teoría y la literatura poscolonial investiga lo que sucede cuando dos culturas chocan y cuando una de ellas, con su ideología, toma el poder y se declara superior a la otra ${ }^{3}$.

La definición de Bressler ayuda a entender lo que el término significa; sin embargo, no debemos pasar por alto su incongruencia y simplismo. Si bien la crítica poscolonial como concepto se origina en círculos anglohablantes y se enmarca en el estudio de literaturas anglófonas, en años recientes muchos críticos que escriben en otros idiomas han comenzado a usar conceptos y estrategias típicas de las teorías poscoloniales en el estudio de literaturas escritas en otros idiomas y contextos tales como los imperios francés, holandés, portugués e incluso el antiguo imperio español. Decir que la crítica poscolonial solamente se ocupa de literaturas escritas en inglés es limitar su alcance.

Bressler generaliza cuando afirma que el poscolonialismo estudia el resultado del encuentro entre dos culturas y lo que sucede cuando

Charles Bressler, Litcrany Criticism: An Introduction to Theory and Practice (New Jersey: Prentice Hall. 1999) 265. 
una cultura se autoproclama superior. En este caso particular, muchas otras teorías y campos de estudio, tanto en el área de la literatura como en la historia, la sociología y la antropología se han ocupado y se ocupan del estudio de la relación entre el imperio y sus periferias, mas no se les considera estudios poscoloniales. Incluso escritores que se han avocado al estudio de temas relacionados al imperialismo y al colonialismo como Franz Fanon o Aimé Césaire -quienes han sido clasificados como escritores anticolonialistas-o Edward Said, Ibrahim Abu Lughod y Eqbal Ahmad -quienes han sido inscritos dentro del análisis del discurso colonialista- no entran estrictamente en la categoría de críticos poscoloniales ${ }^{4}$.

Los críticos poscoloniales son más bien los que, a partir de las elaboraciones de pioneros como Fanon, Césaire o Said, han formulado teorías más complejas para el estudio de la relación entre Occidente y el resto del mundo y para el análisis de literaturas atañidas a esta relación. A pesar de que todos estos críticos entran en la esfera del poscolonialismo, en su mayoría dependen de teorías como el feminismo, el marxismo, el psicoanálisis y la deconstrucción, entre muchas otras. Sus interpretaciones del colonialismo y el imperialismo son mucho más complejas que las de Said o Fanon. Algunos críticos poscoloniales como Dennis Porter o Gayatri Spivak a menudo han criticado, no sin antes reconocer su carácter pionero, a escritores como Said o Fanon por ser muy homogéneos y simplistas en sus conceptualizaciones de las relaciones Occidente-Oriente, y se han inclinado por enfoques más heterogéneos y complicados.

Entre los teóricos poscoloniales contemporáneos más influyentes están Dennis Porter, Gayatri Spivak, Homi Bhabha o Anne

A pesar de que Orientalismo de Edward Said planteó muchas preguntas que más adelante inaugurarían el campo de la crítica postcolonial. algunos de los que han producido las definiciones más convincentes del término -entre ellas Sara Mills- a menudo lo separan de críticos puramente poscoloniales como Gayatri Spivak, Homi Bhabha o Dennis Porter. En los casos de Fanon y Césaire. a menudo se les atribuye ser los primeros en articular cuestionamientos al imperialismo. que se separaran del simplismo marxista de ver el imperialismo en términos puramente economicistas. ignorando cuestiones raciales y culturales. 
McClintock. A pesar de haber muchos teóricos tan importantes como estos, las elaboraciones de estos cuatro son lo suficientemente ilustrativas como para conocer un poco más a fondo las tendencias más prominentes dentro de la crítica poscolonial contemporánea.

Dennis Porter afirma que la visión de Said, homogénea en cuanto a la relación entre Occidente y Oriente, es limitada por cuanto puede convertir al conocimiento colonial represivo que denuncia en todo lo que puede existir para la descripción de las relaciones entre ambos ámbitos ${ }^{5}$. Porter sostiene que no existe una visión unificada del Oriente en los textos colonialistas, y que discursos más heterogéneos -indicados por brechas, contradicciones e inconsistencias- pueden ser detectados al leer literaturas coloniales. En «Orientalism and its Problems», Porter trata de demostrar esta noción al leer los Viajes de Marco Polo y Los siete pilares de la sabiduría de T.E. Lawrence como obras que presentan visiones muy heterogéneas del Oriente, pese a que en Orientalismo Said había catalogado dichas obras como representantes de puntos de vista Occidentales homogéneos sobre el Oriente.

Gayatri Spivak difiere de Said al afirmar que los textos coloniales tienden a representar solo algunos sectores de las poblaciones nativas y no al total de la población, como, según sostiene, sugiere Said $^{6}$. Para Spivak, los textos coloniales a menudo representan un sector muy reducido de las poblaciones autóctonas, dejando así por fuera a muchos otros grupos, en especial a las mujeres. Por lo tanto, su crítica generalmente se centra en la localización de voces que generalmente son ignoradas o marginadas en los textos y literaturas coloniales. Su principal estrategia es analizar narrativas coloniales no solamente leyendo lo que estas dicen acerca de los sujetos coloniales, sino también localizando las omisiones y las ausencias en tales relatos.

\footnotetext{
Dennis Porter. "Orientalism and its Problenı". Colonial Discourse and Post-colonial Theon: Patrick Williams Ed. (Columbia University Press: Nueva York. 1994).

( Sara Mills. Discourse (Londres: Routledge. 1997).
} 
Por otra parte, Homi Bhabha y Anne McClintock parten de la teoría psicoanalítica para describir el proceso de colonización y apropiación en la narrativa colonial. De acuerdo con Sarah Mills, ambos autores han descrito al colonialismo como una forma de desorden patológico a nivel del Estado. Esto hace pensar que la relación entre el país colonizador y el sujeto colonizado se caracteriza por un intenso deseo por un lado y un gran temor por el otro. Al país colonizado se le otorga sexualidad y se convierte en objeto de fetichismo sexual, al mismo tiempo que funciona que repositorio de temores irracionales.

\section{Problemas, dificultades y limitaciones de la crítica poscolonial contemporánea}

Si bien podríamos citar otros teóricos poscoloniales y sus perspectivas en cuanto al colonialismo y al imperialismo, probablemente encontraríamos puntos de vista no muy distintos a los de los cuatro influyentes autores mencionados hasta el momento. Es viable observar la gran diferencia que existe entre estos críticos y autores como Edward Said, Eqbal Ahmad, Franz Fanon y Aimé Césaire.

Las articulaciones teóricas de la crítica poscolonial son mucho más intricadas y heterogéneas que las que otros críticos hayan formulado, con antelación, sobre el mismo tema. También es evidente que la importancia que sus formulaciones le dan a aspectos económicos y políticos se diluye conforme su complejidad aumenta. Debido al hincapié en la heterogeneidad y en los enfoques multidisciplinarios, dichas aserciones se convierten en algo difícil de agrupar y definir como una disciplina unificada. Finalmente, tal y como lo implican las nociones de estos cuatro escritores aquí expuestas, hay una evidente dependencia de teorías posmodernas cuando se trata de articular nociones sobre la realidad, la historia y la política. Son estas características del poscolonialismo las que muestran sus limitaciones, problemas e incongruencias al examinar su modo de análisis de la relación entre Occidente y Oriente mediante el estudio de la literatura y la escritura colonial. 
Vayamos, entonces, al problema de la definición del poscolonialismo. Ni siquiera sus más conspicuos entusiastas pueden decir con certeza lo que realmente quiere decir el vocablo. Para Robert Young, gran parte de la teoría poscolonial de hoy en día es escrita de un modo confuso y de difícil comprensión, caracterizado principalmente por los debates internos entre críticos que se acusan mutuamente de ser cómplices del colonialismo. Young afirma que este debate, sumado a la dificultad de las teorías poscoloniales, más bien apaga las voces de los pueblos poscoloniales en lugar de estimular su articulación y circulación. Además, sostiene que la complejidad de las teorías poscoloniales contemporáneas hace que su enseñanza sea sumamente difícil en las aulas o fuera de las fronteras del mundo académico, especialmente el mundo académico Occidental ${ }^{7}$.

En parte, esta complejidad también se debe a la intersección, dentro de los estudios poscoloniales, de diferentes corrientes filosóficas y teóricas como el marxismo, el psicoanálisis, el deconstruccionismo y el posestructuralismo. Esta gama de perspectivas -que en muchos casos se contradicen entre sí- a menudo se traslapan con crítica y teoría literaria en general, lo que dificulta aún más la unidad del término poscolonialismo. Estos problemas, como se verá luego, también apartan a los estudios poscoloniales de la realidad diaria de los sujetos coloniales y poscoloniales que dicen estudiar a través del escrutinio de textos literarios en donde se retrata su relación con las metrópolis Occidentales.

Otra dificultad en cuanto a los estudios poscoloniales es la excesiva heterogeneidad de sus postulados. Una de las principales diferencias entre las proposiciones de Fanon, Césaire o Said y los de Porter, Spivak o Bhabha es el acento que estos últimos ponen en lo heterogéneo en lugar del dualismo de los primeros. Esto, sin embargo, podría ser más bien una causa más de confusión e incongruencias

Robert Young. Post-Colonialism: An Historical Introduction (Oxford: Oxford University Press. 2003). 
porque a pesar de que los críticos poscoloniales se dicen muy cuidadosos a la hora de escuchar todas las voces coloniales supuestamente suprimidas o ignoradas por críticos como Said, en su heterogeneidad también tienden a generalizar y a limitar el ámbito de sus estudios aún más de lo que teóricos como Said aparentemente lo hacen.

Benita Parry indica que críticos como Spivak han asumido a sectores muy específicos del mundo colonial -como la mujer bengalí atrapada entre los dominios del patriarcado nativo y la ideología masculina del imperialismo extranjero- como representantes de una universalidad colonial ${ }^{8}$. Erin O'Connor también critica las generalizaciones de Spivak, la cual, en su lectura de Jane Eyre de Charlotte Bronte, caracterizada por O'Connor como exigua y parcializada, asume estar estudiando todo un género, cultura, política, la relación entre la novela y Jamaica, India, Irlanda, África, colonialismo, orientalismo y racismo, entre otros ${ }^{9}$.

Finalmente, críticos de los estudios poscoloniales advierten de las implicaciones del término en sí. Algunos piensan que la palabra 'poscolonial' podría llevar a creer que el hecho de que la época de colonialismo masivo sea asunto del pasado y que pueblos previamente colonizados son ahora independientes; entonces, todo el mundo es poscolonial. Robert Young afirma que el prefijo 'pos(t)' complica el asunto "porque implica un 'después' en dos sentidos -temporal, es decir, lo que viene después, e ideológico, es decir, suplantar». Young arguye que la segunda implicación del prefijo resulta debatible porque muchas inequidades del modelo colonialista aún no han sido superadas; un país puede ser poscolonial por ser políticamente independiente pero al mismo tiempo neocolonial ya que aún permanece en un estado de dependencia cultural y económica.

El último problema que el término 'poscolonial' implica en el párrafo anterior puede introducir el dilema de la relación entre los

\footnotetext{
$\overline{8}$ Benita Parry, «Problems in Current Theories of Colonial Discourse». The Postcolonial Studies Reader. Ed. Bill Aschroft (Londres: Routledge. 1995).

9 Erin O Connor. «Preface to a Post-postcolonial Criticism».
} 
estudios poscoloniales y la realidad política y económica de los territorios y los pueblos estudiados a través del análisis literario. Muchos críticos creen que en su preocupación excesiva por encontrar complicadas fórmulas para describir la condición de sujetos coloniales y poscoloniales, los teóricos del poscolonialismo a menudo descuidan las realidades políticas y económicas de los pueblos a los que se refieren. Muchos académicos no occidentales son reacios a adoptar teorías poscoloniales debido a su distanciamiento de la realidad diaria en sus respectivos países. Pensadores no occidentales, como Denis Epko, han expresado opiniones muy críticas sobre las teorías poscoloniales. Epko sostiene que

nada hace que el africano no vea la celebrada condición posmoderna del poscolonialismo como poco más que un grito hipócrita y auto adulatorio de lo niños mimados y sobrealimentados del hipercapitalismo. ¿Entonces, qué tiene que ver la África hambrienta con el disgusto postmaterial de los aburridos y los sobrealimentados? ${ }^{10}$

Por su parte, Arif Dirlik sostiene que los críticos poscolonialistas ven el mundo de un modo que se acerca más a los intereses de Estados Unidos o Europa que a los de los pueblos del tercer mundo. Afirma que los estudios poscoloniales no representan los intereses del tercer mundo, sino más bien los de los estudiosos que defienden las teorías poscoloniales ${ }^{11}$. En otras palabras, el poscolonialismo es insuficiente para describir la realidad de los efectos del colonialismo europeo en la periferia poscolonial de hoy en día. De acuerdo con Dirlik, Parry señala que debido al continuo interés de los críticos poscoloniales en elaborar constructos complicados y abstractos para explicar las circunstancias de los sujetos poscoloniales, quienes están

\footnotetext{
10 Denis Epko, “On Postcolonial Theories». Twentieth Century Literature. Vol. 45. 1999.

1 Arif Dirlik, «The Postcolonial Aura», Postcolonialism: An Anthology' of Cultural Theory and Criticism.
} 
aún hoy en día involucrados en movimientos de resistencia contra formas contemporáneas de imperialismo podrían leer los enunciados de dichos críticos con considerable incredulidad ya que, en la mayor parte de los casos, estos enunciados descuidan los factores socioeconómicos y políticos involucrados.

Algunos de los problemas de la relación entre los estudios poscoloniales y la realidad del tercer mundo surgen del hecho de que prácticamente todos los críticos poscoloniales, tanto en Occidente como en otros lugares del planeta, dependen de teorías filosóficas europeas como el marxismo, el psicoanálisis o el deconstruccionismo, las cuales, a pesar de ser relativamente útiles para describir fenómenos como el colonialismo, no fueron ideadas con ese propósito; por tanto, presentan importantes inconsistencias a la hora de aplicarse al estudio de los efectos del imperialismo y el colonialismo.

Otro aspecto de conflicto en cuanto al poscolonialismo es la relación entre este campo y la posmodernidad. Pensadores marxistas como Frederic Jameson ${ }^{12}$ o David Harvey ${ }^{13}$ ha menudo han afirmado que el poscolonialismo, que aboga por la articulación de una subjetividad colonial y trata de confrontar la hegemonía imperialista, no es más que otro producto de la posmodernidad. Estos críticos sostienen que esta dependencia de teorías posmodernas contradice la idea poscolonialista de confrontar la metrópolis. Ania Loomba afima que

muchos críticos de la teoría poscolonial han acusado a este campo por su excesiva dependencia de perspectivas posestructuralistas y posmodernas (que a menudo se ven como algo idéntico). Arguyen que la insistencia en historias múltiples y fragmentaciones dentro de estas perspectivas ha ido en detrimento del cuestionamiento de las operaciones globales del capitalismo de hoy en día ${ }^{14}$.

\footnotetext{
12 Frederic Jameson, Postmodernism or the Cultural Logic of Late Capitalism (Durham, NC: Duke University Press. 1991).

13. David Harvey. The Condition of Postmodernity: An Enquiry into the Origins of Cultural Change (Malden, MA: Blackwell Publishers, 1990).

It Ania Loomba. Colonialism Postcolonialism (Londres: Routledge, 1998).
} 
Al asociar la posmodernidad con la celebración de los mecanismos del capitalismo -o al menos su consentimiento-, Loomba afirma que críticos como Arif Dirlik o Ahijas Ahmad, junto con pensadores marxistas como Jameson o Harvey, han clasificado al poscolonialismo como una metodología que, al rechazar las pretensiones universalistas del marxismo o las generalizaciones de críticos como Said, termina no con una dispersión hacia lo vernacular y lo local, sino con un retorno a un lenguaje primermundista con pretensiones epistemológicas universalistas incapaces de responder preguntas acerca del capitalismo y otros asuntos contemporáneos. Dirlik llegó a sostener que «el poscolonialismo es la condición de la intelligentsia de capitalismo global» ${ }^{15}$.

Aparte de la presunta complicidad con el capitalismo contemporáneo, la dependencia del poscolonialismo de postulados teóricos europeos (esencialmente la dependencia de la posmodernidad) va en detrimento de enfoques para el estudio del colonialismo y el imperialismo que intentan ir más allá de lo que la perspectiva europea permite. Robert Young apunta que los estudios poscoloniales siguen siendo eurocentristas, dependientes de la filosofía occidental enseñada en la academia occidental e incapaces de rechazar marcos referenciales europeos ${ }^{16}$. Por tanto, la subordinación a la posmodernidad. con todo y las implicaciones de este término, y la dependencia de la epistemología europea en general, son factores que perpetúan la hegemonía europea y convierten al poscolonialismo en un simple ejercicio de pensamiento occidental que eventualmente terminará con poco o nada que ver con el contexto que supuestamente estudia.

\footnotetext{
15 Una opinión parecida of recen pensadores como Slavoj Zizek. Frederic Jameson. Eduardo Gruner, Antonio Negri y Michael Hart. entre otros. acerca de los Estudios Culturales contemporáneos y el multiculturalismo. áreas de estudio relacionadas con los estudios poscoloniales.

16. Entre los que se puede considerar como muy dependientes del pensaniento europeo se podría citar a Edward Said.
} 


\section{Conclusiones y recomendaciones}

Si el poscolonialismo ha de sobrevivir como disciplina que de manera coherente elucide el proceso de colonización y la condición de poscolonialidad mediante el análisis textual, es necesario repensar su metodología. Lo exhaustivo de sus teorías debe estar acorde tanto con las realidades del mundo contemporáneo en general como con las circunstancias políticas y culturales de los pueblos que pertenecen al mundo poscolonial o con los pueblos que aún luchan por su liberación política de formas explícitas de intervencionismo occidental.

A pesar de los enconados debates entre los escritores anticolonialistas de las décadas de 1950 y 1960 o críticos del colonialismo más recientes, como Said y los críticos poscoloniales contemporáneos, estos últimos no deben olvidar el que sus orígenes se inspiran en trabajos como Orientalismo, o en obras aún más seminales como el Discurso acerca del colonialismo de Césaire o Los condenados de la tierra de Fanon. Los críticos poscoloniales no deben descuidar el hecho de que estas tres obras estuvieron, en la época de su publicación, mucho más comprometidas con la realidad política, la historia y la experiencia cotidiana de aquellos que tuvieron que sufrir las consecuencias del imperialismo europeo.

La mayor parte de los críticos poscoloniales contemporáneos manifiestan mucho desinterés en fenómenos como el neoliberalismo, la globalización, el capitalismo multinacional e incluso situaciones extremadamente evidentes que nos conciernen a todos, como el intervensionismo militar y político de algunos países contra otros en formas muy parecidas al imperialismo colonial del pasado. Un campo que abarca el estudio de fenómenos como el imperialismo, el colonialismo, o la apropiación del Otro colonial, no debería desconocer tras todos estos fenómenos hay guerras, generalizaciones racistas, explotación de seres humanos, calamidades humanitarias y muchos otros factores que nos hacen pensar que la teoría en exceso puede ir en detrimento de los propósitos con que se está utilizando. 
La teoría meticulosa puede ser adecuada para ciertas circunstancias, pero la evidencia palpable jamás debe subestimarse. El poscolonialismo debería poner más atención a esta evidencia; de lo contrario, la crítica justificada a este campo continuará creciendo y tornándose cada vez más influyente hasta que los estudios poscoloniales podrían, en un futuro no muy distante, ser recordados como el arte casi mágico de describir al mundo sin realmente verlo, lejos de este, entre libros y cómodas oficinas y bibliotecas de Departamentos de Literatura en universidades occidentales, sobre todo estadounidenses. 